\title{
Past, Present and Future of Process Control at Xstrata Nikkelverk
}

\author{
Tor Anders Hauge ${ }^{1,2}$ Rune Løkling ${ }^{1}$ Stanley M. Haga ${ }^{1}$ \\ ${ }^{1}$ Xstrata Nikkelverk, $\quad$ Servicebox 604, Kolsdalen, $N-4606$ Kristiansand, Norway, E-mail: \\ \{thauge, rlokling, shaga\} @xstratanickel.no \\ ${ }^{2}$ Department of Engineering, Mechatronics Group, University of Agder, N-4898 Grimstad, Norway.
}

\begin{abstract}
MIC celebrates its 30th anniversary in 2009 and Xstrata Nikkelverk celebrates its 100th anniversary in 2010. Both anniversaries are certainly worth celebrating and with this article Xstrata Nikkelverk salutes MIC at this special occasion. This article is about process control developments at Xstrata Nikkelverk during the last 40 years. We also give an overview of the current status and a view on the current and future trends of process control at the Nikkelverk refinery.
\end{abstract}

Keywords: Xstrata Nikkelverk, Process Control, DCS, PLC

\section{Introduction}

Xstrata Nikkelverk is a nickel refinery in Kristiansand, Norway. The primary metals refined are nickel, copper, cobalt and precious metals. The Nikkelverk history (Sandvik, 2004) started in 1910 with Kristiansand Nikkelraffineringsverk. In 1929, the refinery was bought by Canadian company Falconbridge. In 2006, Anglo-Swiss Xstrata PLC bought Falconbridge along with the Norwegian nickel refinery.

A chlorine leach and electro-winning process is used to separate and recover component metals. The refinery processes a granulated matte produced by Xstratas Sudbury smelter in Canada, BCLs smelter in Botswana, as well as custom feed from other sources. The granulated matte is crushed to a very fine powder and then transported to the chlorine leach plant. The metals contained in the matte are separated and distributed to the various process areas for further purification and refining. From there, the products are cut, packaged and shipped to world markets (Stensholt et al., 2001).

The history of process control at Xstrata Nikkelverk goes hand in hand with the metallurgical history of the refinery. The process from 1910 and into the 1970's was the Hybinette process (Archibald, 1962). This process is still used in many nickel refineries around the world. The electro-refining based Hybinette process is hard to automate and thus with the development of the hydrometallurgical matte leaching (ML) (Thornhill et al., 1971) and chlorine leaching (KL) (Stensholt et al., 1985) processes in the 1960's and 70's the application of automation and process control exploded. As of today, only the KL process is used at Xstrata Nikkelverk.

In this paper we will take a look at the history and developments in automation and process control at Xstrata Nikkelverk. We will also summarize the current status and provide our view on some future developments.

\section{Process Control Systems}

\subsection{The Beginning}

The first control room was established as early as in the 1930's with analog controllers and logics. In 1967, the 
refinery became the first Norwegian company to use a Distributed Control System (DCS) for an industrial chemical process. The DCS system was a PDP8 twelvebit machine with 1.5 microsecond cycle time and $2 \times 4 \mathrm{k}$ ferrite core (Thornhill et al., 1971). The DCS system had the name Nikkeline and controlled the new hydrometallurgical ML (matte leaching) process. Other features of Nikkeline were e.g. 124 analog inputs, 64 PI controllers, 14 ratio controllers, 4 weight controllers and 50 valve positioners. According to engineers familiar with the system, the controllers could be quite sophisticated and included both cascaded and split-range controllers. A slightly amusing story about Nikkeline is that two faulty woven ferrite bits made the actual memory slightly less than the specifications, and the engineers had to be careful not to use the faulty bits in the program. A few years later, Nikkeline was replaced by Nikolas, which did not add new functionality or capacity, but it was a PDP8i machine with integrated circuits rather than open cards with electronic components.

Even though the ML process was a huge step forward compared to the Hybinette process, the development of the next generation of nickel refining process, the KL (chlorine leaching) process, appeared shortly after. In the mid-1970's the KL process accounted for almost half of the refined metals. Control of the KL process was roughly divided into an ABB SIGMA-tronic PLC system for the digital controls and a Noratom Nord 10 as DCS system for the analog controls. The Nord 10 operator stations were text-based, without graphics. An important improvement came in 1985 with Nord 100 operator stations with graphic displays. The Noratom system was the preferred DCS system for 12 years at the Nikkelverk refinery.

\subsection{ABB and Siemens win Nikkelverk for decades to come}

On the PLC side Nikkelverk chose Siemens and their Simatic solution despite the early installation of the ABB SIGMA-tronic PLC. First came the PLC-N with hardwired logic similar to the ABB SIGMA-tronic system. The PLC-N system was first used in the new roasting process in mid to late 1970's. Later came Simatic S5 in use from 1985 and S7 from 1996. The PLC's are basically used in the mechanical operations (like cutting, packing, etc) and electric systems (highvoltage, rectification, etc.). The need for operator stations in the PLC systems grew and in $2002 \mathrm{WinCC}$ from Siemens was used in the high-voltage system and then later on numerous PLC systems.

A heated discussion aroused in the mid 1980's on the future of the Noratom DCS system. Eventually it was decided to go for the ABB Masterpiece DCS system and the first implementation was carried out in the roasting and sulphuric acid plants in 1987. Then followed other sections of the plant and in 1995 all Noratom systems were replaced with either ABB Masterpiece or the later ABB Advant (from 1994) DCS system. In the year 2000 the evolution of what is today known as the ABB 800xA DCS system began. The first $800 \mathrm{xA}$ implementation was done at Nikkelverk in 2006, when several transportation units carrying precious metal matte was implemented in the $800 \mathrm{M}$ controller. The Unix based Advant operator stations are approaching the end of their life and the Nikkelverk refinery asked different vendors for offers for new operator stations in 2008. Several vendors submitted their offers based on either ABB's own OPC servers or third party OPC servers. Eventually, ABB won the contract and in 2009-2010 all Advant operator stations are replaced with new Windows based $800 \mathrm{xA}$ operator clients.

Figure 1 summarizes the different DCS and PLC systems throughout the Nikkelverk history.

\subsection{Industrial IT systems}

Historical data storage outside of the traditional DCS system started its history at the Nikkelverk refinery in 1988 with the installation of a Nord 550 machine. In this system, a sampling time of 5 minutes was used and the values were stored for 72 hours. Each day, the time-series were printed on paper and distributed to engineers and others. In 1994 the ABB IMS database was installed and served for many years as the main source for process information at the Nikkelverk refinery. In 2007 a modern time-series database, GE Fanuc Proficy Historian, was bought to collect data from both DCS and PLC systems. With the new $800 \mathrm{xA}$ system, the ABB IM database is used for long-term data storage for the operator clients, while the Proficy Historian is available for engineers, researchers, and others. Besides the increased capacity of a modern database it also provides increased openness for storing data from different systems and it provides tools for direct import of data in e.g. Microsoft Excel. Many people at Xstrata Nikkelverk need information from the process to get their job done effectively. For this purpose, ABB's Adva Inform Display was installed in 1996. Later, in 2007, this was replaced with GE Fanuc's Proficy Portal which is a web based process information system. Both Adva Inform Display and Proficy Portal contain graphical representations of processes (with live values), as well as graphs, trends and customized views. 


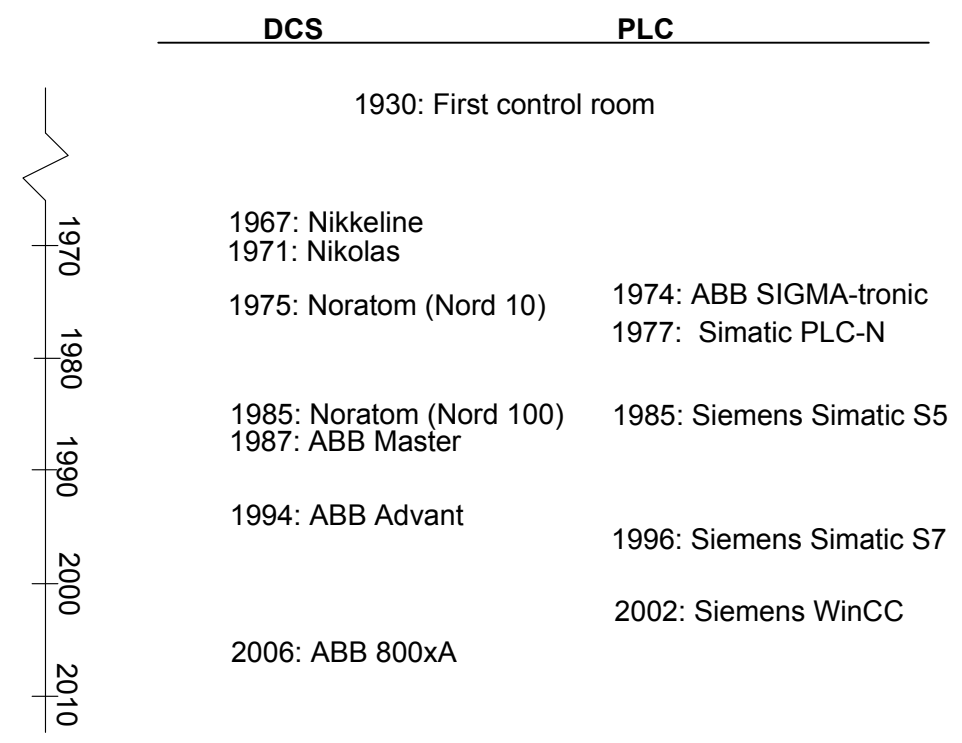

Figure 1: Chronological overview of DCS and PLC systems at Xstrata Nikkelverk.

\subsection{Advanced Control Systems}

In the 1990's, Falconbridge bought a world-wide license for using the Connoisseur MPC (Model Predictive Control) system in all its plants. Connoisseur, from Predictive Control, was installed at the Nikkelverk refinery in 1996. Predictive Control was later bought by Invensys, and Connoisseur is today a product of Invensys. After a hardware failure on the Connoisseur server in 2007, the system was shut down. In 2009 the world-wide license from the Falconbridge era was no longer valid and some vendors were asked to provide offers for a new MPC system. The contract was awarded to Prediktor AS and their APIS system. The MPC system will be installed towards the end of 2009 and the first application implemented in 2010.

\subsection{Communication and Bus Systems}

In this section we will look at communication and bus systems beyond the traditional series connections. Ethernet in the DCS system was first introduced with the Masterbus 300 network in 1987. Master Bus 300 is an ABB proprietary $10 \mathrm{Mbits} / \mathrm{s}$ Ethernet and is used for communication between controllers and operator stations in the Advant DCS system. This network was used for 20 years until switches were introduced to increase the speed to $100 \mathrm{Mbits} / \mathrm{s}$ (still $10 \mathrm{Mbits} / \mathrm{s}$ from the switches to the different nodes on the network) in 2008. With the client/server network, following the installation of ABB 800xA in 2009, a 100 Mbits/s network all the way to the different nodes was established. In 2000, Siemens PLC's were connected to Ethernet and in 2005 Xstrata Nikkelverk was probably the first Norwegian site to use a wireless industrial Ethernet (Wireless Profinet). The wireless Ethernet is used in the nickel electrowinning.

The proprietary Master and Advant DCS systems made fieldbus systems like Master Fieldbus (first used in 1995 in the cobalt refinery) and Advant Fieldbus 100 (first used in 1997 in the ball mill and electrolyte purification sections) the preferred choices in the DCS system. These fieldbuses are used to connect remote I/O stations to controllers in the Masterbus network.

The ASI bus has been used at Nikkelverk since 2006 . Applications of the ASI bus include transportation of precious metal matte, used in the first ABB $800 \times \mathrm{x}$ system at Nikkelverk, and washing and emergency shutdown systems in the electrowinning sections. Profibus DP was used with Siemens S5 PLC's from 1990 and from 1998 also with Motion Control (servo motors). In 2007 the first application of Profibus PA took place in a cooling system for rectifiers.

Figure 2 summarizes the different industrial IT, MPC, and communication systems throughout the Nikkelverk history.

\section{Process Control Organization}

Since the year 2000, the Process Control group at Xstrata Nikkelverk has been responsible for all aspects of PLC and DCS systems as well as instrumentation in projects.

Prior to 1960 all instrumentation and control was carried out within the Electrical Department. How- 


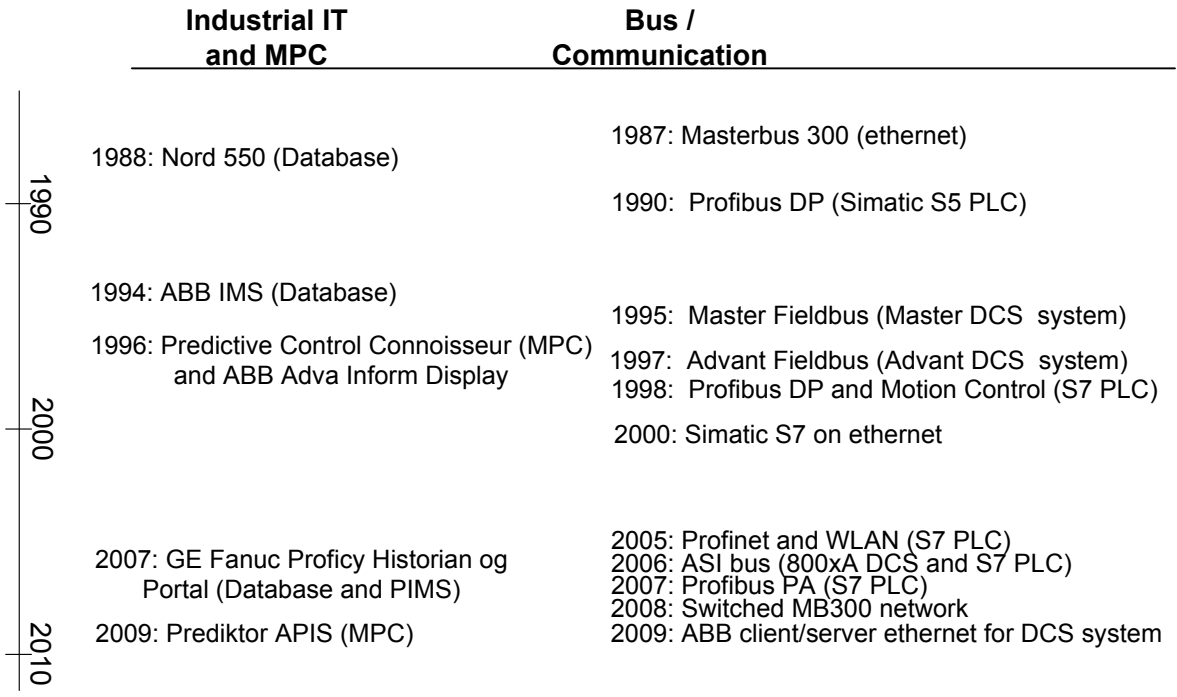

Figure 2: Chronological overview of Industrial IT, MPC and communication systems at Xstrata Nikkelverk.

ever, in 1960 an independent Instrumentation Department was established. With the ML process and Nikkeline DCS system coming, the Instrument Department was also given responsibility for this new system from 1965 .

Even though the PLC systems were used extensively in the 1970's, no department had the formal responsibility for these systems. Probably due to the nature of the hardwired logic in the PLC's of this era, the local electricians did the "programming" and maintenance necessary. In the beginning of the 1980's, the instrument engineers in the Maintenance Department gradually took responsibility for the PLC systems.

In 1982, a new Data Department responsible for IT and DCS systems was established. This department was responsible for both office and DCS computers and networks. In 1992 a Process Control group was established with responsibility solely for DCS systems. A few years later the group was also given the responsibility for PLC systems and then from the year 2000 also the responsibility for instrumentation in projects.

The Process Control group is part of the Technology Department and the shares of hours spent on projects and operational issues are approximately equal.

Figure 3 shows chronologically the organization of the process control group which today encompasses DCS, PLC and instrumentation.

\section{Process Control in 2009}

\subsection{The Process Control group and infrastructure}

The Process Control Group at Xstrata Nikkelverk consists of 10 people. The plant has a modern and extensive infrastructure including:

- 70,000 IO (30,000 in DCS system and 40,000 in PLC systems)

- 1,000 PID controllers in DCS system

- 80 Siemens Simatic S7 PLC's

- 12 WinCC operator stations

- 60 operator panels connected to PLC's

- 3 Kuka Industrial robots

- GE Fanuc Proficy Historian and Web Portal

- Prediktor APIS MPC system

- ABB 800xA / Advant DCS system

- Redundant $100 \mathrm{Mb}$ switched Masterbus and client/server networks

- 9 AC450 and 1 AC800M controllers

- 28 operator clients in DCS system

Looking at the history of process control systems at Nikkelverk it is clear that once a system is chosen we stick with it for many years to come. This approach enables the process control group to handle most projects, 


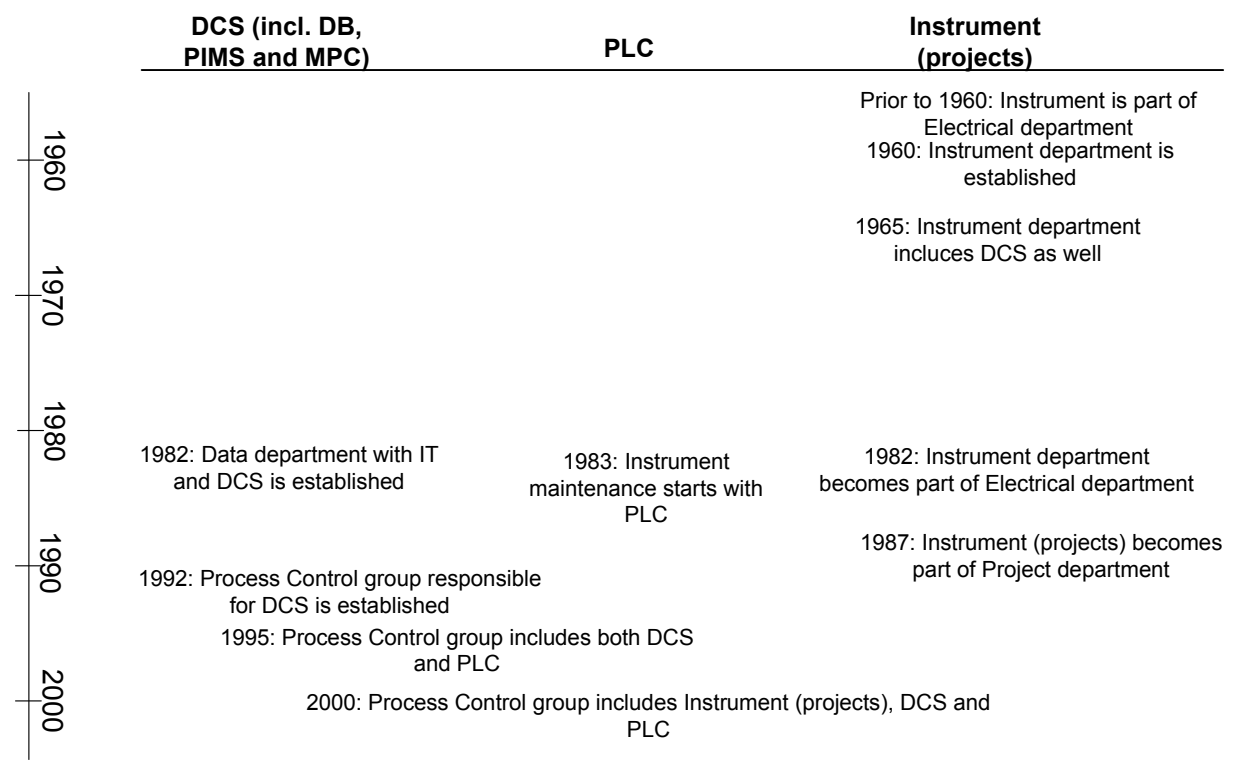

Figure 3: Chronological overview of organization of process control group at Xstrata Nikkelverk.

support and maintenance of the systems without external help. A different approach known at other sites would be to ask DCS/PLC vendors for offers at larger projects, and have several systems on site. This way, one would probably be much more dependent on support and help from the different system vendors.

A consequence of the local foundation of the process control group at Xstrata Nikkelverk is that it is trusted throughout the whole organization. This means e.g. the freedom to try out new control strategies or new technology (e.g. wireless industrial Ethernet). We are sometimes asked how the operators and others respond to frequent changes and new implementations in our DCS and PLC systems. The answer is that most people are positive to these improvements. This is probably due to the local foundation of the process control group at the Nikkelverk refinery that goes all the way back to the days of the pioneering Nikkeline DCS system.

\subsection{Examples of current projects at Xstrata Nikkelverk}

\subsubsection{MPC in the Cu-plant}

Even though the DCS and PLC systems handle most control problems with good results, there are areas where standard PID controllers and logic strive. One typical such example can be found in the $\mathrm{Cu}$-plant.

Copper $(\mathrm{Cu})$ is separated from the nickel $(\mathrm{Ni})$ solution in a cementation and filtering process. The $\mathrm{Cu}$ rich chlorine leach residue is repulped and roasted in fluidized bed roasters. Calcine from the roasters con- tains mostly $\mathrm{CuO}$, but also impurities of $\mathrm{Ni}, \mathrm{Co}, \mathrm{Fe}$ and more. The calcine is transported to the $\mathrm{Cu}$ leaching tanks where it is leached with spent $\mathrm{Cu}$ electrolyte. In the leaching, $\mathrm{CuO}$ reacts with sulphuric acid $\left(\mathrm{H}_{2} \mathrm{SO}_{4}\right)$ and forms copper sulfate $\left(\mathrm{CuSO}_{4}\right)$. In the following filter presses, undissolved $\mathrm{NiO}, \mathrm{CoO}, \mathrm{CuO}$, precious metals, etc, are separated from the leach solution. The dissolved metals are then pumped to scrap columns for further purification. The scrap columns are filled with $\mathrm{Cu}$ metal for cementation of impurities. The impurities are recovered in downstream filters. The purified electrolyte is pumped to electrowinning where $\mathrm{Cu}$ metal is produced at the cathode and $\mathrm{H}_{2} \mathrm{SO}_{2}$ and $\mathrm{O}_{2}$ forms at the anode. Spent $\mathrm{Cu}$ electrolyte is then pumped back to the $\mathrm{Cu}$ leaching to close the circuit. The modeling of the leaching, purification and electrowinning of $\mathrm{Cu}$ metal is described in (Lie and Hauge, 2008) and an overview of the process is provided in Figure 4.

Important quality measurements throughout the $\mathrm{Cu}$ process are the concentrations of $\mathrm{Cu}$ and $\mathrm{H}_{2} \mathrm{SO}_{4}$ (free and available $\mathrm{H}_{2} \mathrm{SO}_{4}$ ). These quantities also represent a challenge to control due to the long time delays and strong couplings. Note that available $\mathrm{H}_{2} \mathrm{SO}_{4}$ is defined as the sum of free $\mathrm{H}_{2} \mathrm{SO}_{4}$ and $\mathrm{H}_{2} \mathrm{SO}_{4}$ available as metal sulfates $\left(\mathrm{MeSO}_{4}\right)$ in the solution. The most important inputs to control these quantities are the tonnage of calcine to the leaching, the flow of new $\mathrm{H}_{2} \mathrm{SO}_{4}$ to the leaching, and the flow of spent $\mathrm{Cu}$ electrolyte to the leaching.

As mentioned in section 2.4, a new MPC system was bought in 2009. In 2010 the Cu-plant model will be tuned (parameter estimation) and implemented in the 


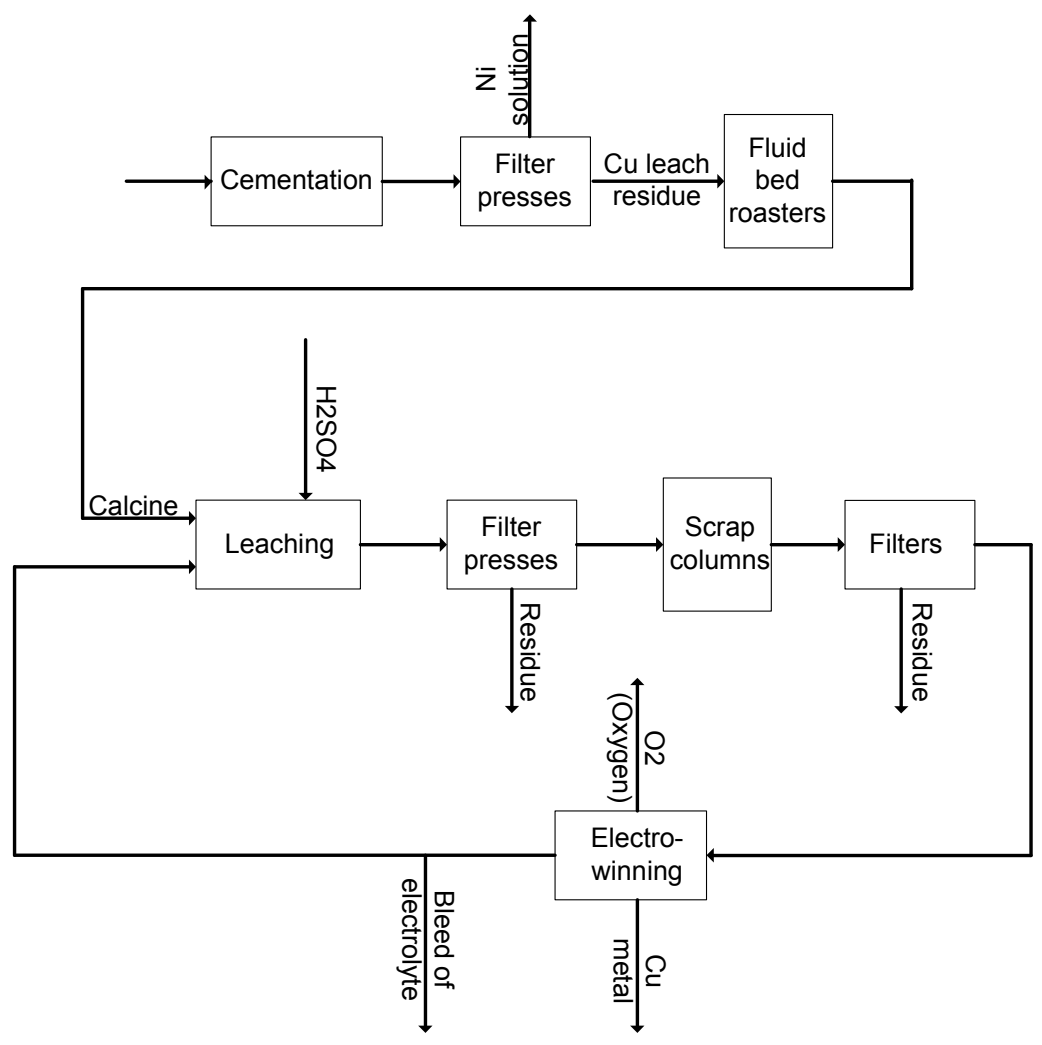

Figure 4: Overview of the $\mathrm{Cu}$ process.

MPC system.

\subsubsection{Operator training simulator for the roasting and sulphuric acid plant}

With increased level of automation and environmental and safety awareness, the need for realistic operator training increases. At Xstrata Nikkelverk this is particularly true for the roasting furnaces and sulphuric acid plant due to the fast dynamics of the process and complexity of both the process and control system. The project of developing the simulator was started in 2009 and will finish in 2011. The project is carried out in cooperation with Telemark University College, Porsgrunn, Norway, where modeling and implementation of the model will be part of a $\mathrm{PhD}$ program. The simulator will be a so-called "hardware in the loop" simulator where the control system is an "exact" clone of the real control system, thus there is no need for modeling of the control system.

Figure 5 shows the main structure for the simulator.

\subsubsection{Automation of filter press valves}

One of the most important and frequently used processes at Nikkelverk is the separation of solid particles from a solution, using filter presses. Most filter presses at Nikkelverk are semi-automatic and require operators to e.g. manually open and close valves when the filter press is changing status from e.g. "Production" to "Water washing" or "Hydrochloric acid washing". In recent years, many of the filter press stages have been equipped with automatic valves. These include stages for separation of $\mathrm{Cu}, \mathrm{Fe}$, and gypsum from the nickel solution. Even though the replacement of manual valves with automatic valves is quite straight forward in itself, it opens a wealth of opportunities for optimization of the precipitation/crystallization, transport, and separation processes.

\subsubsection{Accredited weighing of raw materials and metal for sale}

A new system for electronic registration of raw material and product weights is being built. The weighing platforms are being reused from the old system - apart from that the new system consists of weighing amplifiers, indicators, operator panels, PLC and server. The PLC is communicating with the weighing amplifiers and operator panels using profibus DP. Communication with the server is through OPC (also known as OLE for Process Control). The operation of the weighing program is done in Internet Explorer using standard clients on the LAN network. The weighing program in the server 


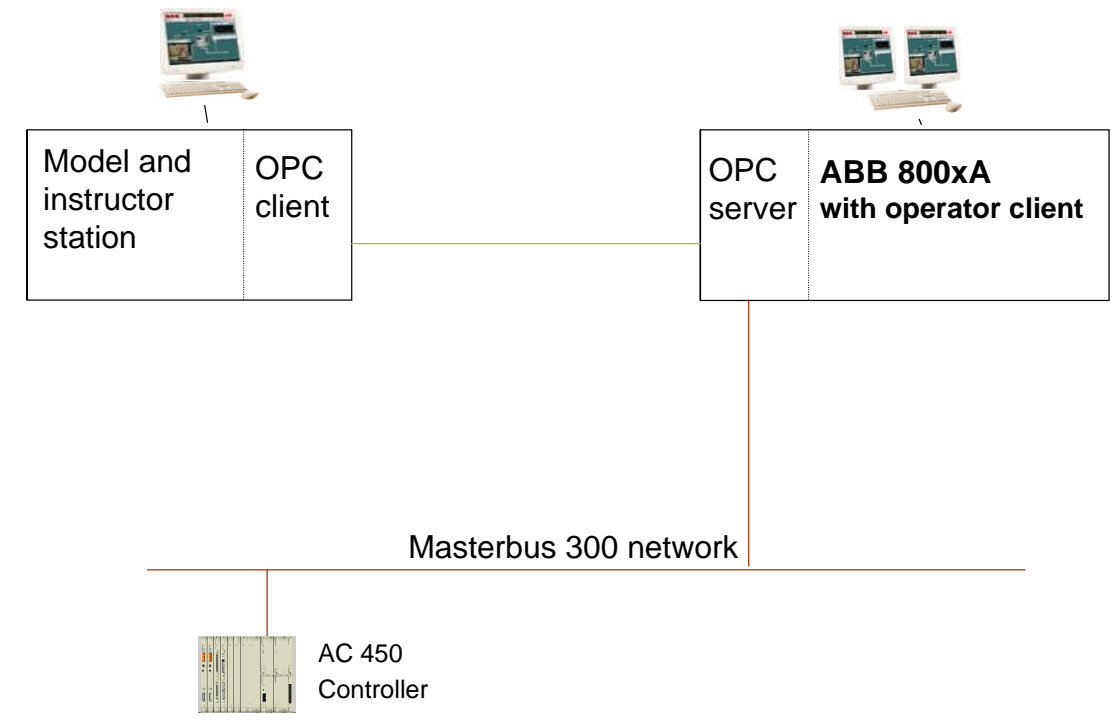

Figure 5: Roasting and sulphuric acid plant simulator structure.

is developed using XML-programming and Microsoft .NET. From the server, the data are transferred to the Xstrata Nickel SAP business system located in Canada.

This project is carried out in close cooperation with the IT Department and partly using their skills and infrastructure. Projects where the process control group carries out work in cooperation with the IT Department is seen more and more often.

\section{Process Control in the future}

Going forward from 2009, what trends are currently the strongest, which trends will emerge in the near future, and which trends will eventually die out unnoticed? Here are a few of the Nikkelverk view on these issues.

\section{Explosive growth in $\mathrm{I} / \mathrm{O}^{\mathbf{1}}$ and data}

One of the strongest current trend is without doubt the enormous growth in measurements, automatic valves, frequency converters, and similar. At Xstrata Nikkelverk, if not every day but at least every week, there is new I/O being introduced into the DCS and PLC systems. One reason for this growth is obviously to be able to control the process better but another important reason is probably the low cost of off-the-shelf equipment today. Some of the equipment provides better insight into the process and better ability to control the process. Others also offer reduced costs. Installing a frequency converter along with a motor provides an additional degree of freedom for control, and also lower energy costs and simpler and more cost effective in-

\footnotetext{
${ }^{1} \mathrm{I} / \mathrm{O}=$ Inputs and Outputs, e.g. measurements and actuators
}

stallation due to built in protective functionality, information about e.g. energy consumption, no need for contactor in the main circuit, and more.

The increased number of measurements, actuators and similar also results in more data available. This, as well as increased openness between systems, the use of international standards like OPC, faster bus systems and Ethernets all contribute to more and more data being available in historical databases. One of the challenges for today and the future is how to make best possible use of all the data.

\section{Robotification}

Robotics in the process industries has a long way to go and so also at Xstrata Nikkelverk. The fact that robot fabrication now is series production and that they are being sold in large numbers makes them attractive also for the process industry. There are several reasons that robotics will be more and more popular at Xstrata Nikkelverk and in the process industries in general: (i) the cost for robots decrease, (ii) the technology improves, (iii) labor cost increase, (iv) it will be harder to find labor for manual work, (iiv) humans are removed from hazardous, noisy, etc. areas.

\section{Direct measurement and control of quality} parameters

A trend which was popular at Xstrata Nikkelverk several decades ago was to establish online analysis that provided direct insight into the quality of the process. This included many dissolved metal and acid concentration analysis in solutions and e.g. $\mathrm{O}_{2}$ and $\mathrm{SO}_{2}$ concentrations in gas. As the need for even better control of the process increase, the need for more and 
better online analysis will increase. One area which may prove very important for us in the future is the ability to measure and control more specific properties of solutions and solids. Typically these properties are measured and controlled indirectly today through bulk properties like $\mathrm{pH}$, redox, temperature, conductivity, etc.

\section{Advanced control}

Model Predictive Control is a proven and reliable technology and the references in the industry are numerous. For some Xstrata references see (Thwaites, 2007). MPC is not the technology you will use for most of your control problems. The standard features of a DCS or PLC system take care of these. However, for the few but important problems where a more advanced strategy is needed, MPC is often the right choice in process industries in general. The number of MPC applications at Xstrata Nikkelverk will increase in the future. We do not see a lot of applications coming, but expect the number to increase steadily.

Expert systems are very popular in the mining and metal industry. It is hard to understand why this is so because the underlying rules can easily be implemented in standard logic in DCS and PLC systems. In addition one would expect to have better results using MPC than an Expert system (Jonas, 2008). We will surely not see any Expert systems at Xstrata Nikkelverk. Our strategy is to use the DCS and PLC systems to the extent possible and take care of the remaining few control issues with MPC.

\section{Fault detection and support systems}

To stay competitive, we need to continuously work to bring the production to a higher level of efficiency, availability and product quality.

Signals or systems in the DCS and PLC systems that provide early warnings, indicate equipment failure, or shuts down equipment before failure occurs and adversely affect operations are getting more and more common. Examples include e.g. protecting pumps by stopping them if the measured flow is low, temperatures in windings or bearings are too high or vibration is too high. Self-diagnostics is also becoming more common in electronic equipment e.g. switches in the control network. The reason for doing this is to reduce maintenance costs and minimize downtime.

Applications for improved decision-making for the operations are other means for reducing downtime, waste, and maintenance costs. Such applications have been around for a while but will be even more common in the future. This includes e.g. monitoring of PID loops $^{2}$ to identify poor control. The closer integration between the control system and IT systems also opens a wealth of possibilities, e.g. by creating hyperlinks in

\footnotetext{
${ }^{2}$ Based on e.g. the Harris index or others
}

the process graphics in the operator station you can access the electrical drawings, the maintenance data, reported problems, zoom in on equipment with a video camera, etc.

\section{Fieldbus in instruments}

In many ways, the introduction of fieldbus has slowed down due to older systems not capable of communicating via fieldbus. As the Nikkelverk refinery goes from the Advant to the $800 x A$ DCS system we anticipate an increase in the use of fieldbus. The one $800 \mathrm{M}$ controller capable of fieldbus communication is communicating with motor starters via ASI bus and Profibus DP, and several PLC's use Profibus PA and ASI bus.

The reason for using fieldbus is twofold: First there is the reduced cabling and associated cost, and then there is the possibility for condition monitoring of equipment on the bus. A challenge for the future is to train people in fieldbus systems so that we are capable of not only installing them but also do troubleshooting.

\section{Wireless networks}

As a pioneer in wireless industrial Ethernet one might expect that we would see this as the future. However, we only see industrial WLANS used in special applications like the one used in the nickel electrowinning at Xstrata Nikkelverk or in non-critical applications. Maybe future generations of control engineers will feel comfortable with wireless networks in an industrial environment but as of today we would not go for this as a general solution. The challenge mentioned for fieldbus, i.e. troubleshooting, is probably an even greater challenge for wireless communication.

\section{System security}

The old DCS and PLC systems were never connected to any outside system or network. The systems were obscure and vendor proprietary. The new systems are typically Microsoft Windows based and connected to the office LAN and from there to the Internet. This represents a huge challenge in keeping the systems secure and free from viruses, hackers, and similar.

The challenge of system security can not be met by the traditional control engineer alone and we have to make use of the skills and services of the IT Department to define the barriers in the control system. This really represents a paradigm shift in the thinking of a control engineer. We are still the application specialists, but when it comes to servers, firewalls, networks, etc., this is the domain of the IT Department. To fully understand the consequences, and taking the proper precautions, when physically sharing network cables and servers with the IT Department, allowing someone to connect via VPN to your control system, etc., is a challenge for any process control group in the future. 


\section{Acknowledgments}

Dr. Ole Morten Dotterud at Xstrata Nikkelverk and professor Bernt Lie at Telemark University College and professor Geir Hovland at the University of Agder are gratefully acknowledged for valuable feedback on this article.

The following people have contributed to the making of the chronological systems and organization overview as seen in figures 1, 2, and 3: Gunnar Sand, Rolf Simonsen, Trygve Kolrud, Terje Hovland, Tom Fredriksen, Britt Holtar, Jarl Folmar Nilsen, Erling Knutsen, Øystein Kolrud, Svein Johnny Nyhus, Arvid Rønning

\section{References}

Archibald, F. The Kristiansand nickel refinery. Journal of Metals, 1962. pages 648-652.

Jonas, R. K. Advanced control for mineral processing: Better than expert systems. In 40th Annual Meeting of the Canadian Mineral Processors, Ottawa, Ontario, Canada, January 22-24. 2008 .

Lie, B. and Hauge, T. A. Modeling of an industrial copper leaching and electrowinning process, with validation against experimental data. In Proceedings SIMS 2008, 49th Scandinavian Conference on Simulation and Modeling, Oslo University college Oct 7-8, 2008. ISBN-10:82-579-4632-X, 2008 .

Sandvik, P. Falconbridge Nikkelverk 1910-1929-2004. ISBN 82-303-0215-4, 2004.

Stensholt, E., Dotterud, O., Henriksen, E., Ramsdal, P., Stålesen, F., and Thune, E. Development and plant practice of the Falconbridge chlorine leach process. CIM Bulletin, 2001. 94(1051):101-104.

Stensholt, E., Zachariasen, H., and Lund, J. The Falconbridge chlorine leach process. In Extraction Metallurgy '85, IMM. London, England, 1985 pages 377398.

Thornhill, P., Wigstol, E., and Weert, G. The Falconbridge matte leach process. Journal of Metals, 1971. pages $13-18$.

Thwaites, P. Process Control in Metallurgical Plants - From an Xstrata Perspective. In IFAC 2007 MMM'0\%, Automation in mining, mineral and metal processing international symposium, Quebec City, Canada, August 21-23. 2007. 